\title{
Las luchas obreras bajo el Pacto Social (1973-1974): el caso de la Federación Gráfica Bonaerense
}

\author{
Working-class struggles under the Social Pact (1973-1974): the of \\ Federación Gráfica Bonaerense
}

\author{
Pablo Ghigliani \\ Instituto de Investigaciones en Humanidades y Ciencias Sociales \\ (Universidad Nacional de La Plata - Consejo Nacional de Investigaciones \\ Científicas y Técnicas), Argentina \\ pablo.ghigliani@gmail.com
}

\section{Resumen}

El artículo aborda las luchas de los obreros gráficos en Argentina durante el Pacto Social del tercer gobierno peronista (1973-1974), a través del análisis de sus determinaciones gremiales y políticas.

\section{Palabra claves}

Federación Gráfica Bonaerense - Pacto Social - clase obrera - sindicalismo - conflictividad laboral

\section{Abstract}

The paper approaches the struggles of printing workers in Argentina under the politics of the Pacto Social of the third Peronist government (1973-1974) by analysing their material and political determinants.

\section{Key words}

Federación Gráfica Bonaerense - Social Pact - working-class - trade-unionism - labour conflictivity 


\section{Las luchas obreras bajo el Pacto Social (1973-1974)}

\section{Introducción}

Durante los años 1973 y 1974, la Federación Gráfica Bonaerense (FGB) se opuso tenazmente al Acta de Compromiso Nacional para la Reconstrucción, la Liberación Nacional y la Justicia Social: no sólo fue, quizás, el primer gremio en denunciar el convenio colectivo de trabajo en pleno Pacto Social, sino que promovió medidas de acción directa en el marco de un plan de lucha por la reclasificación y revalorización de las categorías y el reconocimiento de nuevas ramas en la industria. Como consecuencia, el Ministerio de Trabajo intimó a la FGB en reiteradas oportunidades hasta que finalmente le quitó la personería gremial en agosto, la intervino en octubre y reemplazó por el Sindicato Gráfico Argentino (SGA) en diciembre de 1974. Esta saga represiva es ritualmente citada en la bibliografía, junto al retiro de la personería de las seccionales cordobesas de Luz y Fuerza y el SMATA, como evidencia de la intensificación de la ofensiva del gobierno de Isabel Perón contra la oposición sindical. ${ }^{1}$

Existen estudios detallados de los casos cordobeses, pero no así de la FGB. Este artículo sostiene que el fundamento de la intensa movilización de las trabajadoras y los trabajadores de la industria gráfica en esos años se encuentra en la existencia de una agenda gremial consolidada y compartida por todas las corrientes político-sindicales activas en la rama. Desde la firma del convenio colectivo nacional de 1950, que unificó las negociaciones de las varias actividades que organizaba el sindicato, la dinámica de la conflictividad laboral pasó a estar determinada por la presencia de pisos salariales distintos para tareas y esfuerzos idénticos en los sectores obra y diarios hasta que la aceleración de la innovación tecnológica colocó al proceso de trabajo en el centro de las disputas. ${ }^{2}$ Para mediados de los sesenta, el desfasaje entre la renovada base técnica de la industria y el convenio colectivo se había convertido en una de las principales preocupaciones de las agrupaciones que disputaban la conducción del sindicato. En este contexto, la modificación del cuadro de categorías y ramas emergió como una reivindicación que subsumió, al menos temporalmente, las tensiones generadas hasta entonces por las diferencias sectoriales; avanzaba en la homogeneización y regulación de las condiciones de explotación de la fuerza de trabajo y mejoraba de manera notoria la situación salarial de la categorías más bajas. El reclamo no dejaba de ser una manifestación (aunque novedosa) de la táctica seguida por la FGB desde la unificación del convenio: trasladar a los sectores más débiles los beneficios conquistados por los más fuertes (si hablamos de calificaciones, los linotipistas; si hablamos de sectores, los diarios). Fue este el sustrato material del que se nutrió la dirigencia y el creciente activismo de base a principios de los setenta. La creación de nuevas ramas y la reclasificación de las categorías no fue una opción táctica para eludir el congelamiento salarial impuesto por los gobiernos de Héctor Cámpora y Juan D. Perón. Por el contrario, la

\footnotetext{
${ }^{1}$ Entre otros: Juan Carlos Torre. Los sindicatos en el gobierno. Buenos Aires, CEAL, 1984; Daniel James. Resistencia e Integración. Buenos Aires, Sudamericana, 1990; James Brennan. El Cordobazo. Buenos Aires, Sudamericana, 1994; Héctor Löbbe. La guerrilla fabril. Buenos Aires, Ediciones ryr, 2006; Ruth Werner y Facundo Aguirre. Insurgencia obrera en la Argentina 1969-1976. Buenos Aires, Ediciones IPS, 2006; Luis Brunetto. 14250 o paro nacional. Buenos Aires, Estación Finlandia, 2007. Para una discusión de la implementación y desarrollo del Pacto Social: Marcelo Rougier y Martín Fiszbein. La frustración de un proyecto económico. Buenos Aires, Manantial, 2006.

2 Investigué este problema en Pablo Ghigliani. "Organización de la industria gráfica y conflictividad laboral (1940-1960)”. XIV Jornadas Interescuelas/Departamentales de Historia. Mendoza, 2013.
} 


\section{Pablo Ghigliani}

imposición del Pacto Social vino a entorpecer las negociaciones en marcha al brindar a la patronal la posibilidad de posponer, una vez más, concesiones a las que parecía ya resignada. A su vez, mientras que el contenido gremial de las demandas catalizó la movilización, sus derivaciones políticas tuvieron un efecto contradictorio: fomentaron la unidad en la acción del activismo de izquierda pero dividieron al núcleo dirigente y a las propias bases.

\section{Transformaciones tecnológicas}

La base técnica de la composición de textos - el corazón de la industria continuó estando determinada en la época que nos ocupa por la composición mecánica mediante la utilización de máquinas linotipo, más allá de que desde los años cuarenta, algunas innovaciones habían permitido incrementos en la productividad de los linotipistas mediante la reducción de costos (al permitir al operario ensamblar partes sin necesidad de un técnico maquinista) y tiempo (por la simultaneidad de operaciones automáticas). ${ }^{3}$ Pero la matriz básica de operaciones de las más modernas linotipos (y de su competidora, la Intertype) seguía siendo familiar para un trabajador de principios de siglo XX: una caja de matrices (almacén o magazine), un teclado para seleccionar dichas matrices, un mecanismo para el fundido de las líneas de tipos y un mecanismo de distribución que retornaba las matrices a la caja (almacén o magazine) de manera automática. Por ello, las tareas de los linotipistas (un puesto de trabajo que ocupaba una posición estratégica en la industria) mantuvieron una marcada continuidad durante todo el período a pesar de los adelantos técnicos.

Sin embargo, la difusión durante la década del sesenta de nuevos métodos y tecnologías preanunciaban el cambio de época que experimentaría la rama. En un comienzo, y sin que ello afectara todavía los principios técnicos del sistema de composición en caliente mediante fundición de líneas en plomo, aparecieron las llamadas máquinas ultrarrápidas (las Cometa y Elektron de Linotype y la Monarch de Intertype) las cuales podían elevar la producción a 900 ciclos - composición, fundición, distribución - por hora.

Estos avances estimularon a su vez la propagación del sistema de cinta perforada Tele-typesetter (o TTS), aplicable tanto a las componedores Linotype como a las Intertype, lo que acentuó la automatización en busca de una optimización de los rendimientos al desvincular al operario (que componía el texto en un teclado perforador) de la máquina componedora. La cinta perforada era luego introducida en un dispositivo (el operador automático) que acoplado a la derecha de la componedora traducía los códigos transmitiendo los movimientos a las teclas y atendiendo las funciones normales de la composición: justificación, cambio de redonda a cursiva o viceversa, centrado de líneas, sangría, etc. Un

\footnotetext{
3 El grueso de la información sobre la historia de los procesos productivos de la industria gráfica proviene de: Mergenthaler Linotype Company. The Linotype Line. Brooklyn, 1949; Mergenthaler Linotype Company. The Linotype Maintenance Manual. Brooklyn, 1951; Carles Castro Sanz. La reconversión tecnológica y empresarial en un periódico "consolidado": el caso de "La Vangurdia". Tesis Doctoral. Barcelona, Universidad Autónoma de Barcelona, 2002; Luis Parenti. Linocomposición. Barcelona, Don Bosco, 1972; Euniciano Martín. La composición en las artes gráficas. Barcelona, Don Bosco, 1974; Gianfranco Tonello. Fotocomposición. Barcelona, Ediciones Don Bosco, 1974; y para la situación en la época de la industria gráfica argentina fue fundamental Argentina Gráfica, la publicación trimestral de la Cámara de la Industria Gráfica Argentina.
} 


\section{Las luchas obreras bajo el Pacto Social (1973-1974)}

mecanógrafo podía producir de este modo hasta tres veces más que un linotipista avezado.

Pero a su vez, y casi en simultáneo, cobró impulso lo que se denominó composición en frío, que aplicando los principios de la fotocomposición empleaba película y prescindía de los sistemas de impresión de relieve con plomo; este sistema economizaba mano de obra (suprimía las operaciones propias de la tipografía) y capital fijo (mediante la eliminación del material tipográfico, las inversiones en mobiliario y material de cajas, las prensas de prueba y las instalaciones de refundición del metal). Justamente, las fuertes inversiones existentes en capital fijo retrasaban la ineludible reconversión empresaria. Todas las máquinas de componer (fueran del sistema caliente o frío) podían ser gobernadas manualmente a través de un teclado directo o por mando automático mediante cinta perforada o magnética.

Estos desarrollos combinados amenazaban las bases de poder del linotipista, la figura productiva emblemática de la industria gráfica. Preanunciaban su futura (y pronta) desaparición, al asentar las bases para la aplicación de la microelectrónica y la informática que revolucionarían la industria a principios de la década del ochenta. Una mirada rápida de Argentina Gráfica, basta para ilustrar la plena conciencia de la patronal de la época, sobre el rumbo futuro de la industria.

La fotocomposición condujo de manera directa a la adopción de los mejorados métodos de impresión planográfica offset, beneficiados por los avances en la confección de las planchas de impresión. Aunque los principios de la impresión offset eran conocidos desde principios del siglo veinte su aplicación a la producción encontraba varias limitaciones: no solo las rotativas offset eran sensiblemente más caras y complejas y demandaban un mayor consumo energético sino que muchas de las rotativas tipográficas en la rama eran recientes y se encontraban lejos de haber sido amortizadas. Además, el sistema offset desperdiciaba más papel debido al difícil equilibrio entre tinta y agua que requería el procedimiento, y la confección de las planchas de impresión demandaba mucho más tiempo. Como consecuencia, se desarrollaron sistemas intermedios que procuraban la adaptación de las rotativas tipográficas a la fotocomposición con el fin de aproximarse a la calidad ofrecida por el offset sin prescindir de la tecnología existente. Así, cobró protagonismo en la rama gráfica la flexografía, un sistema cuyo objetivo era prolongar de manera sencilla la vida de las rotativas tipográficas mediante el uso de moldes de plástico o caucho, para adaptarlas a la fotocomposición, y mejorar la calidad de las impresiones, pero manteniendo la impresión en relieve.

La flexografía tomaba su impulso de las estrategias publicitarias dirigidas a captar la atención de los consumidores mediante la sofisticación de la presentación de las mercancías. Aprovechaba nueva técnicas (electrónicas y químicas) y nuevos materiales (celofán, papel aluminizado, polietileno, plásticos). Un número creciente de talleres empezaron a especializarse en la producción e impresión de bolsas y sacos de papeles diversos y materias plásticas, envases y etiquetas varias, calcomanías, cintas de colores, cintas adhesivas de celulosa, cartón liso o corrugado, papel de envoltorio, papel decorativo, plásticos para envasado automático. Hacían uso de máquinas rotativas de impresión simultánea de hasta 6 colores, nuevas máquinas de cortar y rebobinar, máquinas corta-pliegos automáticas, adelantos que aumentaban la velocidad y la automatización. Las 


\section{Pablo Ghigliani}

tradicionales bolsas de papel Kraft marrón y los estuches confeccionados a mano e impresos en las viejas máquinas de litografía fueron quedando rezagados ante el imperativo modernizador del mercado.

Por último, la fuerza de trabajo ocupada en la producción de formularios continuos, una actividad pujante y novedosa en la época, y que por sus especiales características era inclasificable en el cuadro de ramas y categorías vigente en los sesenta, se encontraba en una situación similar a la de aquellos empleados en fotocomposición y flexografía.

En otras secciones (impresión tipográfica o encuadernación, por ejemplo) la maquinización se orientó en idéntico sentido, mayores velocidades por medio de la automatización de procesos, pero sin revolucionar las tareas y las calificaciones de los operarios. Pero los incrementos de la productividad activaron también en ellas, reclamos salariales que incorporaban a sus argumentos, comparaciones entre los valores de las nuevas y costosas maquinarias, los beneficios obtenidos y el atraso de los sueldos.

\section{El desfasaje del convenio colectivo de 1950 y la lucha por su readecuación}

El convenio firmado por la FGB en 1950, el primero de carácter nacional en la industria, compendiaba las distintas tareas y calificaciones derivadas de los desarrollos tecnológicos que habían tenido lugar desde los años treinta. Su articulado contenía no solo una más detallada especificación de las tareas, sino una reorganización general que incluía al conjunto de las ramas en un sistema clasificatorio único de catorce categorías que atravesaba transversalmente a la industria. Este último aspecto fue la gran conquista del gremio en la época: lo unificó integrando los distintos sectores, fortaleció las comisiones de rama elegidas por los afiliados y permitió que el poder de negociación de los más fuertes dentro de la industria repercutiera a favor del conjunto.

No obstante, la difusión de los métodos y máquinas descriptos en la sección anterior alteró en los sesenta la relativa estabilidad que había caracterizado a la base técnica de la industria. Sin embargo, el cuadro clasificatorio de ramas y categorías se mantuvo inalterado por más de dos décadas. El convenio dejó de reflejar la situación de los talleres. La demanda de actualización se instaló en el gremio y se incorporó a los programas y campañas de las distintas agrupaciones sindicales.

La referencia programática más temprana que encontré en la documentación data de noviembre de 1966. Se trata del Plan de Acción electoral de la Lista Blanca que incluía la eliminación de las categorías en desuso, la elevación a categorías superiores de las especialidades desactualizadas y la calificación de las nuevas máquinas ajustando los salarios a los niveles de producción de las mismas. ${ }^{4}$

En el VI Congreso de la FATI de 1967, la representación porteña ya estaba en manos de la Lista Verde, peronista, que se había impuesto en las elecciones de noviembre de 1966. Bajo sus auspicios, en este cónclave se creó una comisión especial para analizar la evolución de la tecnificación en la industria que concluyó

\footnotetext{
${ }^{4}$ Boletín de la Agrupación Gráfica "7 de junio". Lista Blanca, noviembre de 1966. Esta agrupación estaba liderada por un puñado de viejos activistas anarquistas, radicales e independientes que habían roto unos meses atrás con la Lista Rosa, la que conducía al gremio desde el fin de la intervención impuesta por la Revolución Libertadora.
} 


\section{Las luchas obreras bajo el Pacto Social (1973-1974)}

que la automatización mediante el sistema de cintas perforadas agudizaba el problema de la desocupación en el gremio, que dicha actividad debía encuadrarse en el convenio colectivo de los gráficos, y que las máquinas que trabajaban con cintas (mencionaba a las Cometa, Elektron y Linomatic) debían ser supervisadas por linotipistas. ${ }^{5}$ Por su parte, la FGB empezó a reunir y clasificar información técnica y antecedentes internacionales para pedir la creación de la rama flexografía, y al año siguiente, lanzó una campaña por la creación de la rama formularios continuos, con activa participación de activistas comunistas. ${ }^{6}$

En 1968, la FATI solicitó a la Secretaría de Trabajo la constitución de una Paritaria Técnica para tratar los problemas de interpretación y aplicación del convenio. En sus considerandos afirmaba: "Los problemas a los que hacemos mención, se producen justamente en empresas que han incorporado nuevas máquinas y métodos de labor y producción consiguientes, los que se conocen con la denominación de FORMULARIOS CONTINUOS Y FLEXOGRAFÍA, no habiendo categorización efectiva de los personales, alcanzando esta situación a elevada cantidad de obreros y todo ello a causa de que cuando se confeccionó el Convenio de Trabajo no se clasificó la RAMA pertinente, por no existir, en ese momento las nuevas máquinas y métodos que hemos citado".7

En 1969, la FATI volvió a solicitar modificaciones del reglamento, del cuadro clasificatorio y de los beneficios sociales; en 1970, acompañó idéntico petitorio con un paro nacional de actividades, más la creación de una comisión para analizar las transformaciones de técnicas y métodos. La iniciativa recibió la unánime aprobación del plenario de activistas y delegados de la FGB del 4 de diciembre de $1970 .^{8}$ Fue esta comisión la que elaboró el anteproyecto que adjuntó la FATI en 1971 a la reiterada denuncia del último convenio de la industria firmado en el año 1967. Desde entonces, la Federación Argentina de la Industria Gráfica y Afines (FAIGA) había rechazado su renegociación escudándose en el decreto-ley 17.224/67 del régimen militar hasta que a finales de 1970 un nuevo decreto-ley, el 18.887, reabrió la negociación colectiva (aunque muy condicionada por el establecimiento de pautas económicas precisas). ${ }^{9}$

El Anteproyecto contenía una completa reformulación del artículo 19 y una sección final llamada "Modificaciones al cuadro de ramas y categorías" que incluía

\footnotetext{
5 "Asuntos internos se abocó al estudio del grave problema que trae aparejada la tecnificación". Pregón de los Gráficos Argentinos, año I, n²1, Septiembre-Octubre de 1967, Federación Argentina de Trabajadores de la Imprenta.

6 Ver: "Secretaría de Organización ¿Crítica constructiva?", El Obrero Gráfico, 494, Setiembre de 1972. Según entrevista a Raúl Romano, quien trabajaba en un taller de formularios continuos en la época, y participó luego de la comisión paritaria de la rama, fueron los comunistas los que dirigieron la campaña (13 de marzo del 2014).

7 “Solicitóse la Constitución de una Paritaria Técnica, Buenos Aires, 26 de agosto de 1968". Pregón de los Gráficos Argentinos, año II, n 6, Noviembre de 1968, Federación Argentina de Trabajadores de la Imprenta.

8 El Obrero Gráfico, 488, Enero-Febrero de 1971.

${ }^{9}$ El decreto-ley fue publicado en el Boletín Oficial, $\mathrm{n}^{\circ} 22.087$, del 5 de enero de 1971 . Ver también: Julián Simón. "Breve informe sobre la negociación colectiva en la República Argentina". Revista Trabajo; 2, 3, julio-diciembre. Buenos Aires, 2006. La FATI presentó el petitorio el 29 de enero de 1971 como consta en "Ref: denuncia convenio 1/67", Federación de Trabajadores de la Imprenta, expediente 486.036, Archivo Intermedio de la Nación, Fondo del Ministerio de Trabajo, Caja $n^{\circ} 322$, Convenios Colectivos de Trabajo.
} 


\section{Pablo Ghigliani}

nuevas máquinas, métodos y calificaciones. ${ }^{10}$ Eran, en sí, las dos manifestaciones más evidentes de los cambios ocurridos en la industria durante la última década.

En su primera parte, el artículo 19 que llevaba por título "Desplazamiento de mano de obra”, reproducía casi literalmente el viejo artículo 25 del Reglamento de Trabajo y Salarios del año 1940 (que había establecido que la prioridad para el aprendizaje del manejo de las máquinas nuevas le correspondía a los obreros de la especialidad afectados), al que le insertaba a continuación la modificación sugerida por el frustrado anteproyecto de 1966 ("En ningún caso el desplazamiento de mano de obra podrá dar lugar a despidos"). Se buscaba dejar atrás así la matización que la salvedad "dentro de lo posible" había introducido al convenio del sector periodístico del año 1944, formulación que se reprodujo luego en el convenio de 1950. La ambigüedad de la redacción de este artículo constituyó desde entonces una preocupación constante para los dirigentes gremiales que ensayaban diversos juegos de palabras para reforzar la obligación empresaria de no reemplazar mano de obra por maquinaria. ${ }^{11}$

Pero el anteproyecto de 1971 avanzaba en especificaciones técnicas y precisaba en el mismo artículo que las nuevas máquinas de composición mecánica Cometa, Elektron, Monarch (aún en el caso que fueran operadas por los métodos de producción vía cintas perforadas) debían ser “(...) atendidas por linotipistas especializados" quienes tendrían a su cargo "(...) la atención de dos máquinas por turno". La preocupación por el impacto de la creciente automatización quedaba reflejada de manera patente en la última de las especificaciones: "En cada taller existirá una relación de una máquina por el sistema automático por cada diez máquinas con su correspondiente operario del sistema manual". También se señalaba la prioridad de los obreros desplazados (nuevamente se trataba de los linotipistas) para el manejo "de las máquinas TTS, IBM y/o similares introducidas en la industria gráfica por el proceso de trabajo en cinta para composición directa o sistema electrónico (Linofilm, Photon y otras)".12

Por su parte, la sección "Modificaciones al cuadro de ramas y categorías" reflejaba la difusión de los nuevos métodos y sectores. Creaba la rama flexografía que incluía como especialidad a formularios continuos (en documentos anteriores constituían ramas aparte). A impresión tipográfica se le agregaban las especialidades preparación litográfica y offset, e impresión litográfica y offset, que readecuaban la vieja rama litografía a las condiciones presentes. La mecanotipia de TTS, la composición en frío y la fotocomposición eran incorporadas en una nueva rama que fusionaba las viejas y tradicionales ramas del estatuto del gremio: tipografía (que comprendía a tipógrafos, operadores de Ludlow, correctores, fundidores de rayas, tipos y adornos, fundidores de blancos) y composición

\footnotetext{
10 "Modificaciones al reglamento y cuadro de categorizaciones del convenio de trabajo para la industria Gráfica n 38/50 y posteriores actualizaciones”. El Obrero Gráfico, 488, Enero - Febrero de 1971.

${ }^{11}$ El artículo 25 de 1940 decía: "Para toda máquina nueva que importe desplazamiento de mano de obra se dará preferencia, en el aprendizaje, a los obreros de la especialidad que resulten desplazados del trabajo", Reglamento de Trabajo y Salarios, Federación Gráfica Bonaerense. Ver: Convenio Colectivo de Trabajo para la Industria Gráfica (Sector Periodístico: Diarios y Editoriales de Periódicos y Revistas), Federación Gráfica Bonaerense, 1944; “Convenio Colectivo de Trabajo para la Industria Gráfica y sus Afines", El Obrero Gráfico, 383, junio de 1950; "Convenio Colectivo 49/66, expediente 415319”, Archivo Intermedio de la Nación, Fondo del Ministerio de Trabajo, Caja n 295. 12 "Modificaciones al reglamento...", op. cit.
} 


\section{Las luchas obreras bajo el Pacto Social (1973-1974)}

mecánica (en la que se aglomeraban los linotipistas, tipografistas, monotipistas junto a los mecánicos de linotipos y los preparadores de mezcla y limpieza).

El convenio 6/71 firmado en el mes de abril ignoró todo esto; sin embargo, empresarios y trabajadores acordaron mediante una cláusula transitoria (el artículo 62) la conformación de una Comisión Especial de Categorizaciones que debía contemplar " $(\mathrm{t})$ odos los casos o pedidos de categorización relacionados con elementos o maquinarias nuevas incorporadas a la industria no resueltos hasta la fecha, excepto las que se hallen ya clasificadas en el actual cuadro de categorías y/o estuvieren incluidos en otros convenios y/o estatutos especiales". ${ }^{13}$ De este modo, la FGB lograba por vez primera, pasados cuatro años de su primera formulación oficial, que el reclamo por la categorización de la nueva maquinaria y sectores sea incorporado a la mesa de negociaciones.

Las distorsiones producidas por las transformaciones productivas iban más allá de lo salarial: por ejemplo, cuando se votaban las comisiones de rama de acuerdo al estatuto que reproducía el cuadro del convenio vigente miles de obreras y obreros gráficos quedaban sin representación alguna. ${ }^{14}$ La situación era aún peor en los talleres especializados en impresión flexográfica o la producción de formularios continuos.

El programa de la Lista Verde para las elecciones de la FGB del mes de mayo de 1972 enfatizaba la necesidad de cambiar el cuadro de ramas y categorías y la vigencia plena de la ley 14.250.15 Un mes más tarde, los delegados del congreso de la FATI volvían sobre la cuestión al discutirse el tema del convenio. Los documentos que alcanzaron estado público reflejaban que continuaba la búsqueda de la fórmula precisa para el artículo 19 que obligara a los empresarios a mantener los puestos de trabajo. Pero que mientras cambiaban un verbo por otro, se abandonaban todas las especificaciones técnicas del anteproyecto presentado en 1971. El único agregado de importancia fue la incorporación del sistema offset en caliente y frío al cuadro clasificatorio de ramas y categorías. En este congreso, las desavenencias políticas entre la FGB y otros sindicatos gráficos del país, culminaron con la división de la FATI. ${ }^{16}$

Una vez consumada la ruptura, la FGB retomó a finales de 1972 el anteproyecto abandonado por la FATI, y con él, las especificaciones técnicas (a las que sumó la perforadora IBM de formularios continuos), el pedido de categorización de la maquinaria moderna (comprimiendo el número de categorías) y la creación de nuevas ramas o especialidades (offset, composición en frío y fotocomposición, celofán y polietileno, flexografía, formularios continuos y empleados administrativos). Las diferencias existentes entre el artículo 50 del anteproyecto y el nuevo cuadro clasificatorio que lo acompañaba impiden mayores precisiones (aunque es posible deducir también que tipografía y composición mecánica volvían a conformar ramas separadas). Pedía, además, ascensos de una,

\footnotetext{
13 “Convenio 6/71”, El Obrero Gráfico, 489, Marzo - Abril - Mayo de 1971.

14 Boletín, Federación Gráfica Bonaerense, Julio de 1971.

15 "Lista Verde de los Gráficos", propaganda electoral, Lista Verde, Mayo de 1972.

16 El análisis de este acontecimiento excede los objetivos del artículo. La versión de la FGB es profusamente reflejada, entre muchos otros documentos, en El Obrero Gráfico, 494, Setiembre de 1972 y en la Memoria y Balance del año 1972. Razones opuestas en: "Por qué se desafilió de la F.A.T.I. la Federación Gráfica Bonaerense", Agrupación Gráfica "7 de junio", Lista Blanca, volante, noviembre de 1972.
} 


\section{Pablo Ghigliani}

dos o más letras para distintas categorías, y la propuesta contaba, una vez más, con el apoyo de las corrientes político-sindicales activas en el gremio. ${ }^{17}$

Esta vez, el convenio colectivo se firmó muy rápidamente. Con fecha 5 de febrero de 1973, ambas partes, con la supervisión de funcionarios públicos acordaron que las condiciones económicas, es decir los salarios, regirían entre 1 de enero y el 31 de diciembre de 1973, mientras que las condiciones de trabajo, bajo el nombre condiciones generales, regirían hasta el 31 de diciembre de 1974, tal como lo había determinado el gobierno mediante el decreto-ley 19.872/72. La cantidad de beneficiarios se cifraba en 25 mil obreros, el artículo 19 seguía en busca de una redacción definitiva, las catorce categorías no fueron puestas en entredicho y se prorrogaba el artículo 62 provisorio. Su número de registro fue $12 / 73.18$

Más que nunca, ante la imposibilidad de discutir las nuevas ramas y la clasificación de tareas en una mesa de negociación reducida en la práctica a lo salarial, la estrategia de la conducción de la FGB pasaba por llevar estas reivindicaciones a la Comisión Especial de Categorizaciones, con un ojo puesto en la elecciones de marzo venidero, en la que daban por descontado el triunfo del peronismo.

\section{La reformulación de la disputa bajo el Pacto Social}

A solo cinco días de la asunción de Héctor Cámpora, el 30 de mayo de 1973, la FGB solicitó la conformación de la Comisión Especial de Categorizaciones a las autoridades. Dos meses más tarde, el 30 de julio, luego de numerosas negociaciones, la Comisión comunicaba al Ministerio de Trabajo los acuerdos alcanzados para las ramas formularios continuos y composición en frío y armado. La nota no consignaba categorías pero clasificaba las tareas en rangos numéricos que denotaban los diferentes grados de calificación. Y exactamente un mes más tarde, el 30 de agosto, hacía lo propio para la rama flexografía. El otorgamiento definitivo de las categorías para cada una de las tareas pasó entonces a manos de la Comisión Paritaria (según lo establecía el artículo 50 del convenio).

Entremedio, más precisamente el 8 de junio, había tomado cuerpo definitivo la política de concertación social mediante el Acta de Compromiso Nacional para la Reconstrucción, la Liberación Nacional y la Justicia Social refrendada por la Confederación General Económica y la Confederación General del Trabajo (CGT) en el mismo Parlamento. Desde las páginas de su revista, la FGB había alertado tempranamente sobre las diferencias entre el proyecto "cegeista" y el proyecto de la clase obrera. ${ }^{19}$ Confirmada la orientación del gobierno y el apoyo de la CGT, la

\footnotetext{
17 Como se desprende de la información existente en la prensa del gremio sobre los plenarios de delegados y activistas. Ver también, para los comunistas: "Compañeros y compañeras gráficos", Movimiento Gráfico Unitario, Lista Marrón (adh. C. N. Intersindical), 21 de abril de 1972.

18 Archivo Intermedio de la Nación, Fondo del Ministerio de Trabajo, expediente 519430 y complemento 531.378/73, convenio colectivo 12/73, firmado por la FGB, la FAIGA y AEDBA. Decía el nuevo artículo 19: "Para toda máquina que importa desplazamiento de mano de obra, se procurará dar preferencia en el aprendizaje a los obreros de la especialidad que resulten afectados". El artículo 50, por su parte, incorporaba a las ramas Formularios Continuos y Flexografía.

19 "Dorso tapa: La batalla técnica: un frente de lucha", El Obrero Gráfico, 496, Enero - Febrero de 1973.
} 


\section{Las luchas obreras bajo el Pacto Social (1973-1974)}

conducción del gremio apuntó sus cañones al Pacto Social. El primero de los dieciséis puntos del programa de objetivos inmediatos, con que la FGB convocó al paro general del 31 de agosto, reclamaba la "plena vigencia de la Ley $14.250 \mathrm{y}$ exigir que la Comisiones Paritarias discutan los derechos sociales y salariales de la clase trabajadora. Estos derechos no pueden ser anulados por ningún tipo de 'pactos sociales' (...)".20

Para colmo, la propuesta empresaria elevada en setiembre a la Comisión Paritaria resultó un fiasco ya que no alcanzaba siquiera los niveles salariales que se venían pagando de hecho en la industria. Como consecuencia, se produjo una escalada en la larga pelea por el reconocimiento cuando las asambleas de las tres nuevas ramas rechazaron la oferta y votaron medidas de fuerza: corte de las horas extras, y si no se obtenía respuesta, paros de una hora por turno para la realización de asambleas informativas. El conflicto latente en las comisiones bipartitas se deslizaba así a los talleres de las nuevas ramas en un escenario político y social convulsionado por al retorno del peronismo al gobierno.

Por un lado, las expectativas generadas en el seno de la clase obrera por el triunfo del Frente Justicialista de Liberación Nacional (FREJULI) acicateaban la movilización tensando las relaciones laborales. Por el otro, el Pacto Social apoyado por la CGT acotaba el campo de maniobras de las direcciones sindicales, en especial, de las peronistas. Dar rienda suelta a las demandas obreras, darles dirección y forma por medio de un programa, era la vía más rápida para la confrontación con el Ministerio de Trabajo en manos de un hombre de la Unión Obrera Metalúrgica y las 62 Organizaciones Peronistas; pero contenerlas, avivaba a la multifacética oposición por izquierda que se propagaba en los lugares de trabajo a una velocidad inédita. La bibliografía ha tratado ampliamente el tema (ver, entre otros, nota 1).

En la industria gráfica, además, la división de la FATI, había dejado a la FGB al frente de la negociación del convenio colectivo para la Capital Federal. El sindicato porteño era conducido por un heterogéneo grupo de dirigentes peronistas, que bajo la influencia y el liderazgo de Raimundo Ongaro, hablaba de sindicalismo de liberación, y que desde fines de los sesenta, venía elaborando una amalgama discursiva antiburocrática y anti-imperialista que mezclaba en dosis variables, peronismo, cristianismo, socialismo y revolución. El protagonismo alcanzado desde la conducción de la CGT de los Argentinos en 1968 y 1969 había dotado al gremio de un ascendiente que trascendía su poder estructural. Su capacidad de perturbar la salida de los diarios contribuía también a la visibilidad de sus medidas de fuerza. La activación popular que siguió al Cordobazo tuvo a los gráficos entre sus actores, como se desprende de la escalada de la conflictividad en la industria, en particular bajo la forma de acciones directas, desde la toma del Establecimiento Gráfico Palermo en diciembre de $1970 .{ }^{21} \mathrm{Y}$ aunque los acentos discursivos de la dirección del gremio pudieran cambiar ligeramente según las circunstancias, la tendencia manifiesta de sus actos era hacia la radicalización. Tras el triunfo de Héctor Cámpora, la FGB reafirmó el rumbo combativo, orientación que mantendría bajo la presidencia de Juan D. Perón.

\footnotetext{
20 Organización, Suplemento de El Obrero Gráfico, n 7, Setiembre de 1973.

21 Pablo Ghigliani. "La conflictividad laboral en la industria gráfica (1966-1976): una aproximación"; Alejandro Schneider y Pablo Ghigliani (compiladores). Sobre trabajadores y el mundo del trabajo. Buenos Aires, Imago Mundi, 2015 (en prensa).
} 
A fines de setiembre de 1973, todavía en medio de las tratativas paritarias por la categorización y los salarios de las nuevas ramas, y cuando despuntaban las primeras medidas de fuerza contra la oferta patronal, el gremio gráfico se convirtió, además, en uno de los primeros, sino en el primero, en denunciar un convenio colectivo desde la vigencia del Pacto Social. Era la manifestación concreta de su abierta oposición al congelamiento salarial apenas días antes de la asunción de Juan Domingo Perón. Con esta decisión, lo gremial y lo político se articularon de un modo explosivo tensando la situación para afuera y dentro del sindicato. La organización de bases y el activismo en los talleres, predicados por el ongarismo desde su llegada a la conducción, se enriquecieron con el progreso de nuevas corrientes político-sindicales revolucionarias. Como contracara, la unidad del gremio comenzó a resquebrajarse, poco a poco, por arriba y por abajo, ante la negativa de parte de dirigentes, activistas y trabajadores a enfrentarse a un gobierno al que sentían propio. ${ }^{22}$

En este marco, las dilaciones de la FAIGA, sus contrapropuestas apenas mejoradas, llevaron a un recrudecimiento del conflicto: los paros fueron creciendo gradualmente en intensidad hasta alcanzar las cuatro horas por turno. ${ }^{23} \mathrm{El}$ Ministerio de Trabajo aplicó entonces la conciliación obligatoria a partir del 23 de octubre. El acuerdo llegó, finalmente, a mediados de noviembre, tras dos meses y medio de pelea. Reconocía y categorizaba a las ramas de flexografía, formularios continuos, y fotocomposición y/o composición en frío y armado; y se calculaba en tres mil sus beneficiarios. Una vez homologado debía incorporarse al convenio colectivo $12 / 73$.

Pero la disputa continuó en los escritorios. La Asociación de Editores de Diarios de la Ciudad de Buenos Aires (AEDBA) rechazó el acuerdo atribuyéndose la representación de las empresas del sector periodístico. En realidad, como denunciaba la FGB, expresaba la oposición de los diarios La Razón y La Nación. El argumento esgrimido era que los operadores de máquinas de composición automática de originales periodísticos ya se encontraban categorizados en el convenio alcanzado con el Sindicato de Prensa y la Asociación de Periodistas de Buenos Aires. En los hechos, se trataba de un indicador más del modo en que el cambio tecnológico venía corroyendo la posición del gremio gráfico, y en particular, de los linotipistas. Las empresas del sector periodístico habían comenzado a incorporar el sistema TTS en la década del cincuenta bajo la operación de administrativos, básicamente, dactilógrafas. El artículo 16 del convenio 73/74 que definía el escalafón pare el personal administrativo de prensa incluía a los perforadores de cintas y tarjetas y a los operadores de computadoras,

\footnotetext{
22 La adscripción al peronismo revolucionario la Agrupación Gráfica Sindical - Lista Verde, y las secuelas de la derrotada huelga de Fabril Financiera de 1969, ya habían producido disensiones internas, y el alejamiento de varios activistas históricos de la agrupación. En 1971, algunos de ellos animaron la Agrupación Gráfica Peronista y la Lista Celeste y Blanca, que sin inserción de base, derivó en una derecha desbocada: "No caigamos en la tentación de violar el Pacto Social (...) No tengamos sentimentalismo: apoyemos la sentencia de la AAA para que sean fusilados Ongaro, Tosco, Jaime, Salamanca, Firmenich, Quieto, Di Pascuale, Guillán, Greco, Coral, Atilio López, Gaggero, Galimberti, Cesio, Angelelli, y la gran comparsa de delincuentes trosco-marxi-clasi-comu-montoanarco-mao-guevaristas", volante (sin título), Alianza Antiimperialista Argentina. Juventud Sindical Peronista. Lista Celeste y Blanca en apoyo del Pacto Social CGT-CGE, agosto de 1974. Con todo, se la arreglaron para obtener 682 votos en abril de 1974, poco más del $12 \%$ de los emitidos. El Obrero Gráfico, 501, Junio de 1974. No es ellos a los que alude el final del párrafo.

23 "Rango y mida en la paritaria técnica", El Obrero Gráfico, 499, Agosto - Setiembre - Octubre de 1973.
} 


\section{Las luchas obreras bajo el Pacto Social (1973-1974)}

mientras que el artículo 23 definía al sector de composición como aquel integrado por los trabajadores de perforación de cintas de originales periodísticos, computadoras y composición automática. ${ }^{24}$ La negativa de AEDBA empantanó la homologación pero no impidió que la FGB se lanzara a la firma de acuerdos sectoriales (por ejemplo, con la Asociación de Fabricantes de Formularios Continuos) que fueron consolidando las conquistas alcanzadas para las nuevas ramas. ${ }^{25}$

Resumiendo, la FGB se encontraba a comienzos de 1974 en una situación contradictoria. Por un lado, había obtenido importantes conquistas en la Comisión Paritaria, que venía consolidando mediante acuerdos sectoriales, aunque siguiera en suspenso la homologación ministerial. Por el otro, la denuncia simultánea del convenio en pleno Pacto Social había abierto un impredecible frente de conflicto, que el gremio radicalizó al levantar en el mes de enero un frondoso programa de demandas que, sin dudas, expresaba la decisión política de un sector de la dirección de la FGB de ir hasta el fondo en la lucha contra el Pacto Social, luego de los éxitos alcanzados en las nuevas ramas $y$, desde el punto de vista exclusivamente salarial, también en algunos diarios importantes. La decisión sometía la unidad gremial a mayores presiones, mientras que ganaba en la coyuntura el apoyo del activismo revolucionario. ${ }^{26}$

Dos eran los puntos más conflictivos, aunque no los únicos, del nuevo programa de demandas. Primero, la reclasificación del cuadro de ramas y categorías. El sindicato proponía, "el paso previo y básico" decían sus documentos, que las 14 categorías pactadas en 1950 se redujeran a 10, lo que se traducía en ascensos generalizados del personal. Según el petitorio, las primeras cuatro letras A, B, C y D, debían pasar a constituir la nueva letra A; el resto de las letras iba ascendiendo de a tres: por ejemplo, la $\mathrm{E}$ pasaba a la $\mathrm{B}$, la $\mathrm{F}$ a la $\mathrm{C}$, etc., y las últimas dos, $\mathrm{M}$ y N, a la J). En un futuro cercano, auguraba el gremio, se debería proceder a una nueva reclasificación para reducirlas a siete siguiendo los criterios aplicados en las nuevas ramas. Segundo, la actualización de los valores de cada una de las diez categorías propuestas. El empeño del gremio en subrayar que se trataba de la recuperación del poder adquisitivo perdido y no de un aumento salarial no pasaba de un mero sofisma. ${ }^{27}$

24 "Ref: Expediente $N^{\circ}$ 531.378/73 - Comisión Especial de Categorizaciones. Artículo 62 de la Convención Colectiva de Trabajo para el personal gráfico $\mathrm{N}^{\circ} 12 / 73$ ", Asociación de Editores de Diarios de la Ciudad de Buenos Aires, 15 de noviembre de 1973. Archivo Intermedio de la Nación, Fondo del Ministerio de Trabajo

${ }^{25}$ Organización, Suplemento de El Obrero Gráfico, n 8, Diciembre de 1973.

26 Un apoyo que se expresa en numerosos documentos. Ver: "La lista Marrón se dirige a los compañeros gráficos", Movimiento Gráfico Unitario - Lista Marrón (adh. C. N. Intersindical), 22 de enero de 1974; “Ante la situación nacional. Ante el peligro de intervención de la Federación Gráfica Bonaerense. Ante las elecciones de nuestro gremio", Agrupación Gráfica Organización y Lucha, solicitada, Diario Noticias, 24 de abril de 1974; "A los compañeros gráficos ante las elecciones del gremio", Juventud Gráfica Peronista (integrante de la Juventud Trabajadora Peronista), solicitada, Diario Noticias, 26 de abril de 1974 (también distribuida como volante de fábrica); Compañeros gráficos, Frente de Trabajadores Gráficos, Partido Socialista de los Trabajadores, julio de 1974; La Lista Gris al gremio gráfico, 1 de abril de 1975 (el Movimiento de Delegados y Activistas - Lista Gris fue un frente conformado el Partido Socialista de los Trabajadores, Política Obrera y el Partido Comunista, cuyo objeto fue disputarle las elecciones de abril de 1975 a la lista de las 62 Organizaciones).

27 Esta fue la línea de argumentación defensiva ante las intimaciones ministeriales: $A$ los compañeros gráficos y al pueblo argentino. Nuestra Respuesta al Ministerio de Trabajo, solicitada, 10 de julio de 1974, Federación Gráfica Bonaerense; Interponen Recurso - Ley 20.615, art. 45, 
Durante el primer trimestre de 1974, la conducción de la FGB legitimó en plenarios y asambleas este programa. El año comenzó con una arenga de Raimundo Ongaro a los delegados y activistas en enero, y continuó con la aprobación por unanimidad del programa por un plenario de delegados en febrero y una Asamblea General Ordinaria en marzo. ${ }^{28}$ Hasta agosto, cuando el Ministerio finalmente cumplió con la reiterada amenaza de retirarle la personería gremial, la conflictividad en la rama estuvo íntimamente ligada al problema de las categorizaciones, una derivación de las transformaciones tecnológicas, potenciada en el contexto del Pacto Social por objetivos político-sindicales más amplios. Por un lado, por la negativa de algunos talleres de las ramas flexografia, formularios continuos y fotocomposición a pagar la nuevas categorías. Los primeros de este tipo datan de finales de 1973 (por ejemplo, La Parafinadora Argentina y Celoprint). Algunos, incluso, amagaron con el cierre (Lamson Paragon, Oucinde, Verlini) y fueron ocupados. Por el otro, por la campaña por la reclasificación y revalorización de las categorías.

El enfrentamiento con el gobierno terminó dividiendo a la conducción, a los dirigentes de base y a los trabajadores. El 26 de junio, cinco miembros de la CGA, entre ellos el mismísimo Secretario General, Jorge Zakour, renunciaron en medio de una asamblea general convocada para votar un plan de lucha. Comisiones internas de fábricas importantes (Fabril Financiera, Códex, Bianchi, Atlántida, Estrada, Platt) defeccionaron, total o parcialmente, como consecuencia. Analizar la repercusión en las plantas es más difícil. Es posible afirmar que la mayoría de los talleres acató en un principio las decisiones de la asamblea y que el ongarismo encontró firmes bases de apoyo en aquellos que habían luchado por el reconocimiento de las nuevas ramas, y en algunos grandes diarios, como La Nación y Crónica. Pero también que fábricas importantes desertaron de inmediato: los afiliados de Fabril Financiera, Heliograf y Rotog Arg fueron expulsados del gremio en masa por ello. ${ }^{29}$ Otros casos son más complejos. El personal de Alemann, por ejemplo, $o$ al menos parte del mismo (imposible saberlo con exactitud) se habría plegado al plan de lucha contra la voluntad de sus delegados. ${ }^{30}$ Varios documentos incluyen a Editorial Atlántida entre los que boicotearon las acciones dispuestas en la asamblea de junio; sin embargo, Zakour habría fracasado cuando intentó sumar a los trabajadores de la fábrica a la marcha que se dirigió al Ministerio de Trabajo en octubre pidiendo la personería para el nuevo sindicato. ${ }^{31}$ El taller se encontraba dividido y existía una oposición organizada, derrotada por escasos votos en la elección de delegados de 1973. Pocos meses después, en abril del año siguiente,

presentado a la Cámara Nacional de Apelaciones del Trabajo por Oscar Francomano (Secretario General) y Justo Aragundi (Secretario de Organización), agosto de 1974. La primera intimación a la FGB de la que tengo conocimiento, de las varias emitidas por el Ministerio de Trabajo entre mayo de 1973 y agosto de 1974, se remonta al 18 de julio de 1973, y fue motivada por una denuncia de la patronal del diario La Nación. Acta labrada en el Ministerio de Trabajo, expediente 532.922/73, Comunicado, Asociación de Periodista de Buenos Aires, 20 de julio de 1973.

${ }^{28}$ El Obrero Gráfico, Suplemento Extraordinario, Enero de 1974; Plenario de Delegados de la F.G.B, Federación Gráfica Bonaerense, $1^{\circ}$ de febrero de 1974; Asamblea General Ordinaria del 22 de marzo, Federación Gráfica Bonaerense, s/f.

29 Resumen de la Resolución adoptada por la Comisión General Administrativa separando de nuestro gremio a elementos patronales y carneros, Federación Gráfica Bonaerense, julio de 1974.

${ }^{30}$ Avanzada Socialista, 110, julio de 1974.

${ }^{31}$ Avanzada Socialista, 110, julio de 1974; Reunión -PST, Comité Ejecutivo, Partido Socialista de los Trabajadores, 2 de julio de 1974; Defendamos nuestra organización sindical: la Federación Gráfica Bonaerense, Agrupación Gráfica Lista Naranja, octubre de 1974. 


\section{Las luchas obreras bajo el Pacto Social (1973-1974)}

delegados de Atlántida formaban parte de la Lista Gris, opositora a la Lista Azul y Blanca de la Agrupación Gráfica Peronista Francisco Calipo, incorporada a las 62 Organizaciones y encabezada por Jorge Zakour. ${ }^{32}$ También delegados de Alemann, Platt y Códex, cuya comisión interna, como la de Atlántida, había figurado entre los expulsados de finales de julio. Más arduo aún, es penetrar en las fricciones que la división de la cúpula pudo haber atizado en aquellos talleres que siguieron fieles a la FGB. Pero el tiempo (y sobre todo las decisiones del Ministerio de Trabajo, claro) jugaban a favor de los partidarios de las "62". En octubre, diecisiete comisiones internas estampaban su firma en una solicitada convocando a una asamblea para aprobar los estatutos del nuevo sindicato y su ingreso a la CGT. Contaba también con la adhesión de otras veintisiete fábricas. Mientras que es imposible evaluar el alcance preciso de estas adhesiones, es indudable que la Calipo había logrado ampliar sus bases de apoyo. ${ }^{33}$

Lo cierto es que a partir de agosto, la disputa por la reclasificación quedó desplazada por las protestas contra el retiro de la personería gremial, corroídas, a su vez, por las deserciones. Así y todo, la reclasificación mantuvo su presencia discursiva como parte del programa general de demandas hasta que la intervención y liquidación de la FGB redujo drásticamente la capacidad de movilización de la conducción desplazada, ahora en la clandestinidad, y con su principal dirigente, Raimundo Ongaro, bajo rejas. ${ }^{34}$

\section{La reclasificación luego de la intervención}

El arraigo de las reivindicaciones gremiales movilizadas por la conducción de la FGB encuentra pruebas adicionales en el programa levantado por la Agrupación Francisco Calipo. El grupo disidente rechazó de plano los métodos del ongarismo, pero su discurso no abandonó los reclamos. Para finales de agosto de 1974, una solicitada que acusaba a la CGA del gremio por "atentar contra el Gobierno Popular elegido por más de siete millones de votos”, afirmaba: “...estamos de acuerdo en reclamar reivindicaciones, disentimos en la forma de solicitarlo". ${ }^{35}$ En noviembre, otra solicitada de la Calipo, que buscaba contrarrestar la prédica de las Coordinadoras Zonales Gráficas en las que se cobijaba desde la liquidación de la

\footnotetext{
32 Todos por la Recuperación del Gremio, Lista Gris (volante), abril de 1975.

33 Al gremio gráfico, solicitada, 8 de octubre.

34 Como lo testimonian: Al Pueblo y a las Autoridades Nacionales, Trabajadores de Crónica, agosto de 1974; Comunicado de la F.G.B., Federación Gráfica Bonaerense, 14 de setiembre de 1974; Al Gremio Gráfico, Agrupación de Base La Nación, 16 de setiembre d 1974; No hay represión que pueda cambiar la voluntad de los gráficos, Federación Gráfica Bonaerense, setiembre de 1974; A las compañera y compañeros gráficos, Coordinadora Gráfica Zona 7, octubre de 1974 En verdad, la demanda de reclasificación se mantuvo como motivo central de los volantes y boletines del ongarismo más allá de liquidada la organización: A la clase trabajadora y al pueblo, solicitada, Agrupaciones Base de "Crónica" y "La Nación"; Lista Verde a los compañeros, Agrupación Lista Verde; 1 de noviembre de 1974; A lo compañero gráficos, Federación Gráfica Bonaerense y Coordinadoras Zonales, 12 de noviembre de 1974; Comunicado al gremio gráfico y a nuestro pueblo, Agrupación Lista Verde, 3 de marzo de 1975; A los compañeros gráficos, Federación Gráfica Bonaerense, 24 de marzo de 1975; "La lucha por el convenio", Desde la Base. Boletín de los Trabajadores Gráficos de La Nación, año 1, n 3, 30 de abril de 1975; Las bases de federación gráfica bonaerense reclamamos, Federación Gráfica Bonaerense y Coordinadoras Zonales, mayo de 1975. 35 Qué queremos los Gráficos?, solicitada, Agrupación Gráfica Peronista Francisco Calipo, agosto de 1974.
} 


\section{Pablo Ghigliani}

FGB, el grueso del activismo ongarista y militantes de otras organizaciones, volvía sobre el tema: “...dejamos desierta la asamblea del 26 de junio último por no estar de acuerdo con los métodos que se pretendía imponer para lograr reivindicaciones QUE NUNCA HEMOS ABANDONADO (...) DENTRO DE LA LEY TODO; FUERA DE LA LEY NADA, nos constituiremos, para discutir con los patrones las reivindicaciones de reducción de letras y recategorización de maquinarias modernas que siempre hemos defendido y que obtendremos en el terreno que mejor les conviene a los trabajadores, respaldados por las 62 ORGANIZACIONES y la CGT". 36

A principios de 1975, Jorge Zakopur, a esta altura Secretario General provisorio del SGA, insistía ante la perspectiva de la futura negociación colectiva: "Queremos un convenio que dignifique al trabajador gráfico, un convenio serio y profundo. El que está en vigencia rige desde 1950 y la tecnología en esta industria avanzó tanto que la situación de un operario es hoy completamente diferente. Por eso repito que revisaremos el convenio desde la primera hasta la última cláusula". ${ }^{37}$ Ya de cara a las elecciones de abril de 1975, la propaganda electoral de la Calipo destacaba en su primer párrafo que estaban logrando la "reclasificación y reducción de categorías (...y la...) legalización de maquinarias posteriores a 1952".38

En realidad, para mediados de 1974, un número importante de talleres ya habían accedido a una u otra de las demandas enarboladas en el programa de reivindicaciones aprobado por el gremio en la asamblea general de marzo. El recurso presentado por la FGB contra el quite de su personería gremial, calculaba en más de 60 los talleres en esa condición, y para comprobarlo, solicitaba inspecciones en Celoprint, Profumo, Papelbril, Honegger e Hijos, Anthony Blank, Rotográfica Argentina, Quela, o en los Diarios La Nación, La Razón, Crónica, Freie Press, etc. ${ }^{39}$ Un mes antes, una solicitada del gremio reclamaba "que los dieciséis mil gráficos que no obtuvieron reclasificación o revalorización sean tratados con los mismos niveles de dignidad ya logrados por cuatro mil gráficos en sus condiciones de trabajo". ${ }^{40}$ En la prensa militante, incluso, se sugería que Zakour, antes de renunciar, había arreglado ya los talleres en los que tenía influencia (Fabril Financiera y Códex). ${ }^{41}$ En realidad, en varios de los bastiones del ongarismo se habían obtenido idénticas demandas (por ejemplo, en los diarios y en los talleres de flexografía y formularios continuos).

\footnotetext{
36 Al Gremio Gráfico, Sindicato Gráfico Argentino (adherido a la CGT), noviembre de 1974. Reproducido parcialmente en Documentación e Información Laboral, n 177, noviembre de 1974, como un comunicado de la Agrupación Gráfica Peronista Francisco Calipo. La expresión "dejamos desierta" era una simple expresión de deseos retrospectivos, en realidad todas las fuentes concuerdan en que sólo una minoría abandonó la asamblea junto a los renunciantes.

37 Documentación e Información Laboral, n 180, febrero 1975.

38 No nos detenemos en contestar agravios, Agrupación Gráfica Peronista Francisco Calipo, abril de 1975.

39 Interponen Recurso - Ley 20.615, art. 45, presentado a la Cámara Nacional de Apelaciones del Trabajo por Oscar Francomano (Secretario General) y Justo Aragundi (Secretario de Organización), agosto de 1974.

${ }^{40}$ A los compañeros gráficos y al pueblo argentino. Nuestra respuesta al Ministerio de Trabajo, 10 de julio de 1974. La referencia a que más de sesenta talleres habían obtenido ya las reivindicaciones se repite en las declaraciones públicas de la FGB durante los meses de julio y agosto: Conferencia de Prensa de los Gráficos, 23 de julio de 1974; Gráficos: fraternalmente unidos en defensa de nuestros derechos, solicitada, Federación Gráfica Bonaerense, agosto de 1974.

41 Puro Pueblo (columna Sabino Navarro), n 4 - segunda quincena de agosto de 1974.
} 


\section{Las luchas obreras bajo el Pacto Social (1973-1974)}

Como sea, es evidente que quien aspirara a liderar el gremio no podía desentenderse de una demanda que las trabajadoras y los trabajadores habían hecho propia.

El acuerdo finalmente alcanzado el 24 de junio de 1975 incorporó las ramas de flexografía, formularios continuos y fotocomposición acordadas en 1973 (pero nunca homologadas debido a la oposición de AEDBA) y adoptó un cuadro clasificatorio de diez categorías en reemplazo del viejo esquema (pero no el ascenso generalizado que había acompañado al reclamo hasta la intervención de la FGB). ${ }^{42}$ El Convenio Justicialista para el Gremio Gráfico de 1975 fue la primera renovación integral desde 1950.43

No deja de ser significativo, que en el origen del mayor conflicto del año 1975, ya en pleno reflujo de la conflictividad en la rama, es posible encontrar, una vez más, la cuestión de las categorizaciones. Su desconocimiento por el taller La Ley provocó un conflicto, que la represalia patronal agravó con el despido de 120 operarios, y que duraría - ocupación, negociación y actos de violencia mediante hasta los albores de marzo de 1976. Fue el más virulento pero no el único originado por el reconocimiento de las categorías conseguidas en el convenio durante 1975. 44

\section{Conclusión}

El principal propósito de este artículo ha sido desvelar el trasfondo gremial de la conflictividad laboral en la industria gráfica durante el Pacto Social, a partir de la convicción de que sus facetas políticas son mucho más conocidas, y de que esta operación analítica es un prerrequisito esencial para indagar el modo en que se articularon variables materiales y políticas en la determinación de la dinámica y la forma de la movilización obrera en la rama.

La intención subyacente ha sido la investigación de determinaciones que suelen ser cruciales en los estudios de caso, pero que no encajan en las historias generales del movimiento obrero, concentradas en los aspectos políticos que rodearon a las luchas de esos años. En estos últimos, la movilización del gremio gráfico cobra relevancia como una evidencia más de la existencia de oposición sindical al Pacto Social y de la ofensiva gubernamental para suprimirla. En este estudio, en cambio, el objeto es la propia movilización (y sus fundamentos materiales). Sin entender la larga disputa pre-existente alrededor de los cambios operados en el proceso de trabajo y la inadecuación del convenio colectivo, su

\footnotetext{
${ }^{42}$ Boletín $n^{\circ} 1$ de la Federación Grafica Bonaerense, volante. Allí se criticaba ácidamente el acuerdo alcanzado: "establecieron una reducción de categoría que fue el viejo sueño de la patronal, o sea la creación de la aristocracia obrera, o la división proclive que se perdiera la solidaridad entre los trabajadores. Esto pretenden lograrlo en base al gran salto diferencial que implica que un $80 \%$ del gremio se encuentre entre l letra J y la letra F, un $10 \%$ entre la letra $\mathrm{E}$ y la letra D, y un $10 \%$ entre la letra C y la letra A".

${ }^{43}$ El Obrero Gráfico (nueva época), 5, Septiembre de 1975. El artículo 23 sobre desplazamiento de mano de obra decía que el mismo: "no podrá ser invocado por la empresa como causal de despido", formulación por la que el gremio venía bregando desde 1966 con la esperanza de acotar así las maniobras patronales, como se señaló oportunamente.

${ }^{44}$ Por ejemplo, conflictos de este tipo hubo en Ramos Mejía, Lesagüe, Justo Rodero, Crufer. Ver: Alternativa Gráfica, Órgano del Frente de los Trabajadores Gráficos del Partido Socialista de los Trabajadores adherido a la Lista Gris, Agosto de 1975.
} 


\section{Pablo Ghigliani}

dinámica flota en el aire. No obstante, este sustrato material no explica de por sí, la aceleración y la forma del movimiento. Para ello es necesario incorporar el contexto político y social, incluida la naturaleza de la dirección ongarista y la proliferación de un variopinto activismo de base; también, las tensiones y divisiones generadas en el gremio por la propia acción. El zakourismo no fue una invención del Ministerio de Trabajo, aunque su apoyo haya sido decisivo en la coyuntura; cables de inteligencia sugieren que el grupo disidente buscó activamente el respaldo ministerial. ${ }^{45}$ A su vez, la construcción de una dirección alternativa viable no pudo desentenderse, como lo prueba la documentación, del sustrato material de fondo. Pero sí pudo, con dificultad por cierto, encorsetar la dinámica de la movilización en formas subordinadas a los objetivos del sindicalismo cegetista.

Asimismo, desde una perspectiva analítica y temporal más amplia, el proceso descripto en estas páginas forma parte de la historia de la resistencia a las transformaciones tecnológicas que socavaron las bases de poder de la figura productiva más representativa y estratégica en la industria gráfica durante más de medio siglo: el linotipista, al que la computarización de los años ochenta, le daría el definitivo golpe de gracia. Esta faceta no es ajena a la lucha emprendida por la FGB en un contexto político crecientemente desfavorable; por el contrario, contribuye a dotarla de sentido. Los linotipistas, de fuerte ascendiente en la rama, al sentirse amenazados, se movilizaron con decisión. En el pasado, cuando la lucha se focalizaba casi exclusivamente en los aspectos salariales, eran justamente los linotipistas y los tipógrafos de los diarios los que presionaban para cerrar acuerdos favorables en el sector periodístico y, en el lenguaje del gremio, parcializar las huelgas. Desde la unificación del convenio en 1950, todas las direcciones gremiales intentaron volcar durante las negociaciones colectivas, el poder estratégico de linotipistas y tipógrafos a favor de los sectores más postergados; pero durante las huelgas, este mismo poder se transformaba en el talón de Aquiles de la movilización cuando escapaba al control de los dirigentes, y el sector periodístico dejaba al sector obra aislado y librado a sus propios recursos.

Sin embargo, las (otrora privilegiadas) condiciones laborales y salariales de los diarios se habían deteriorado relativamente durante los sesenta y la difusión del TTS comenzaba a amenazar a los linotipistas; muchos de los perforadores de cintas ni siquiera eran reconocidos como gráficos. Quizás por eso, los llamados ongaristas a la organización de las bases germinaron en el sector. Las comisiones inter-sindicales de gráficos y periodistas atizaron importantes luchas salariales que confluyeron durante la segunda mitad de 1973 con la pelea de los trabajadores empleados en las nuevas ramas, quienes se encontraban por fuera del convenio, en su mayoría concentrados en talleres especializados, y que venían bregando por su reconocimiento desde hacía años. Paulatinamente, las desavenencias del pasado parecían esfumarse. ${ }^{46}$

La reclasificación y revalorización del cuadro de ramas y categorías, que procuraba replicar la exitosa negociación llevada a cabo en flexografía, fotocomposición y formularios continuos, fue la demanda que condensó y canalizó las distintas aspiraciones. Encontraba fundamento material en los cambios operados en la explotación del trabajo que afectaban, con sus diferencias, a todos

\footnotetext{
${ }^{45}$ Archivo DIPBA, Mesa "B", Factor Gremial, carpeta n 126 , Legajo n 73 , folio 40.

${ }^{46}$ Como destaca la nota "Ni Obra, Ni Diarios... ¡El gremio Gráfico Ya está Unido!", Organización, Suplemento de El Obrero Gráfico, nº 7, Setiembre de 1973.
} 


\section{Las luchas obreras bajo el Pacto Social (1973-1974)}

los sectores. Implicaban, no olvidarlo, mejores salariales sustantivas para casi todos, pero fundamentalmente, para los peores pagos. Y permitió que el sector periodístico y el sector de obra, nuevas y vieja ramas, trabajadores y trabajadoras de las más diversas especializaciones, jóvenes y veteranos, abrazaran una agenda gremial común. La táctica no era enteramente nueva en lo que hace a la generalización de las mejores condiciones; más novedosa, en cambio, era la búsqueda de una mayor homogeneidad en el consumo productivo de la fuerza de trabajo para suscitar la unificación de los intereses. No es un dato menor, en una industria en la que permanecían abiertas las heridas provocadas por la parcialización de las huelgas de 1956 y 1966, y en la que aún eran visibles los rastros de las añejas rivalidades de oficios.

Además, el estudio confirma el alto grado de movilización de la clase obrera, el inusitado crecimiento del activismo de base, y la expansión en los talleres de las más diversas corrientes político-sindicales de la izquierda, del peronismo revolucionario, y en este caso en particular, también de un renovado anarquismo. En esto, se emparenta con las investigaciones recientes sobre la clase obrera de aquellos años. Se diferencia, quizás, hasta cierto punto, en que el vuelo rasante del enfoque teórico y metodológico aquí adoptado ilumina mejor la otra cara de la moneda: las tendencias conservadoras existentes en el propio seno de la clase obrera. El conservadurismo no fue ni un patrimonio exclusivo de las conducciones, ni un atributo inmóvil. Los cambios en el escenario, produjeron cambios en los actores. La confrontación con el gobierno peronista dividió a los talleres y a la conducción; el macartismo y los llamados a la moderación, antes estériles, fructificaron con el zakourismo; plantas fuertemente movilizadas entre $1971 \mathrm{y}$ 1973, defeccionaron en 1974. Es más, después de todo, fue el cambio de escenario producido por el Pacto Social, lo que hizo posible transformar una demanda gremial en curso, en un arma políticamente explosiva.

Por último, y para terminar, es imprescindible volver a subrayar, para evitar cualquier malentendido, que fue la represión la causa directa de la caída de la conducción ongarista; el argumento aquí desarrollado, no necesita de inferencias contrafácticas, no hay motivo alguno para suponer que el zakourismo habría logrado imponerse al ongarismo, en el mediano o largo plazo, sin la violencia del Ministerio de Trabajo. Pero ello no agota la cuestión. Para julio de 1974, el gremio estaba dividido y la disciplina sindical rota. Y esta última, no es una afirmación contrafáctica, sino una comprobación empírica, que evidencia la compleja interacción de las determinaciones gremiales y políticas que influyeron sobre la dinámica y la forma de la movilización de los obreros y obreras gráficos, en un escenario cambiante.

Recibido: 01/07/2015

Evaluado: 08/08/2015

Versión Final: 28/08/2015 